\title{
5S NA ORGANIZAÇÃO INDUSTRIAL: PRIMEIRO PASSO PARA A CERTIFICAÇÃO DA ISO 9001:2008 EM UMA MOVELEIRA
}

\author{
PRATES, Glaucia Aparecida ${ }^{1}$ \\ TÚLIO, Lucas de Oliveira ${ }^{2}$ \\ RAPETE, Evandro Foltran ${ }^{3}$
}

Recebido em: 2011-04-26

Aprovado em: 2011-10-24

ISSUE DOI: $10.3738 / 1982.2278 .591$

\begin{abstract}
RESUMO:_Os sistemas de gestão de qualidade baseado na ISO 9001: 2000 tem a intenção, através da sua exigência de que os consumidores se tornam conseguiu satisfazer, as empresas se tornarem mais competitivas no mercado em concorrência. Assim, este estudo teve como objetivo descrever o processo de implementação das técnicas $5 \mathrm{~S}$ como uma ferramenta de gestão da qualidade do sistema empreparação para a ISO 9001: 2008 em uma empresa de móveis do setor. A metodologia é estudo de caso como uma abordagem qualitativa. A partir deste estudo, podese concluir que ocorreu uma motivação através da aceitação de trabalhadores após a implantação do $5 \mathrm{~S}$ e quadros informativos, procedimentos e organização da fábrica. Além desses, foram observadas ações e áreas de trabalho e uma melhor produtividade.
\end{abstract}

Palavras-chave: Sistema de Gestão da Qualidade. ISO 9001: 2008. 5S

SUMMARY: The quality management systems based on ISO 9001: 2000 have the intention, through its requirements that consumers become satisfied, businesses become more competitive in the market in competition. Thus, this study aimed to describe the process of implementing the $5 \mathrm{~S}$ techniques as a quality management system tool on preparation for ISO 9001: 2008 in a furniture company in the sector. The methodology is case study as a qualitative approach. From this study, we conclude that occurred a motivation through the workers acceptance after $5 \mathrm{~S}$ implementation and information boards, procedures and factory organization. Beyond those, were observed a better productivity and reduced work area optimized

Keywords: Quality Management System. ISO 9001: 2008. 5S.

\section{INTRODUÇÃO}

A norma ISO 9001:2008, como modelo de gestão da qualidade, requer a identificação e o gerenciamento de diversas atividades do sistema; uma delas é a elaboração de documentação específica que comprove, perante clientes ou outras entidades, que a empresa tem seus processos normalizados e que esses atendem aos requisitos estabelecidos pela norma. Mesmo que o mercado não exija um certificado, a implantação criteriosa dos requisitos de gestão estabelecidos nessa norma aumentará a eficácia e eficiência da empresa

\footnotetext{
${ }^{1}$ Prof.a Dr.a da UNESP. Doutora em engenharia de produção e sistemas

${ }^{2}$ Engenheiro Industrial Madeireira. UNESP

${ }^{3}$ Graduando em Engenharia Industrial Madeireira
} 
na consecução de sua missão, o que certamente impulsionará ao aumento da competitividade do negócio, pois a real implantação dos requisitos normativos nos processos conduz a empresa à uma maior organização e padronização, reduzindo a variabilidade e demonstrando grande potencial de produzir com qualidade.

Como em outros ramos, o setor moveleiro também está passando por esta fase de busca incansável pela inovação, otimização, flexibilidade estratégica e busca de maior satisfação de seus clientes. Por tais motivos a implantação da gestão de qualidade buscando uma certificação no setor moveleiro se torna item primordial e essencial para sobrevivência organizacional no mercado.

Para a realização plena da implantação da ISO 9001 são necessários registros procedimentos documentados, alem da preparação da organização para a mudança dos processos operacionais e gerenciais. Como preparação da empresa em estudo implantou-se o $5 \mathrm{~S}$ como sensibilização dos colaboradores e preparação para implantação dos requisitos da NBR ISO 9001;2008.

Uma definição comum de 5S no ocidente é housekeeping (CHIN E PUN, 2002; DA SILVEIRA, 2006 ). Uma estrutura de aplicação do 5S em negócios tratado como uma filosofia de vida foi primeiramente formalizada no inicio dos anos 80 por Takashi Osada (HO et al. 1995).

A prática do $5 \mathrm{~S}$ objetiva incluir valores de organização, utilização, limpeza, padronização e disciplina no local de trabalho (OSADA, 1991). No Japão a prática do 5S foi iniciada no setor de manufatura e então difundida para outras indústrias e setores de serviços. O sistema de Produção da Toyota fornece um exemplo bem conhecido dos princípios do $5 \mathrm{~S}$ na prática, as primeiras versões foram baseadas nos 3S e após tornou-se $5 \mathrm{~S}(\mathrm{OHNO}, 1988)$. A Boeing nos Estados Unidos utilizou o $5 \mathrm{~S}$ como uma estratégia mundial (ANSARI E MODARRESS, 1997).

O presente trabalho tem como objetivo: descrever o processo de preparação de uma indústria moveleira situada em São Paulo- SP, para a implantação de um sistema de gestão da qualidade baseado na ISO 9001: 2008 ramo moveleiro utilizando o 5S como ferramenta, de organização industrial.

\section{BENEFÍCIOS DA IMPLANTAÇÃO DO USO E CERTIFICAÇÃO ISO 9000:2008.}

Para Dick (2000), dado o crescimento em ISO 9000 a melhoria do desempenho empresarial é um benefício reivindicado por todas as empresas certificadas. Estas empresas 
voluntariamente esperam que os padrões ISO lhes ajudem a melhorar as coisas e lhes provenha um benefício real. $\mathrm{O}$ autor acima descreve que os padrões britânicos esperam que a empresa tenha maior responsabilidade e consciência de qualidade entre seu pessoal, maior facilidade para controlar e melhorar as atividades empresariais, além de um melhor uso de se tempo e recursos para auxiliar em sua rastreabilidade de produtos e serviços; menor perda de produtos por não conformidade em seus trabalhos, procurando melhoria contínua e sem interrupção de sua qualidade e eficiência, desta forma o lucro vem através de melhores oportunidades de mercado.

Ainda segundo Dick (2000) O RAB (Registrar Accreditation Board) organização reconhecida nos EUA, descreve alguns benefícios internos e externo muito semelhantes ao Reino Unido, para se implementar um sistema de gestão baseado na ISO 9000, estes incluem: melhoria da eficiência operacional; redução de custos das perdas e retrabalhos; qualidade percebida pelo mercado, aumento do Market Share, estas contribuições foram citadas por diversos gurus da qualidade.

Jacobson; Aaker 1998 apud Dick (2000, p. 370), concluíram que a qualidade de produto levou à uma influência positiva em retorno do investimento através de mercado e preço. Uma investigação em 65 empresas na indústria de móveis indicou que a qualidade levou à melhoria da conformidade à especificação e foi relacionado significativamente ao crescimento de vendas e o retorno do capital. Estes estudos indicam o impacto poderoso que uma melhor conformidade pode ser usada para reduzir custos e atraindo e retendo clientes.

Dick (2000) descreve ainda que encontrou evidência que empresas que buscaram o certificado de qualidade somente por necessidades comerciais obtiveram menor resultados em relação àquelas que implementaram com objetivo de melhorar seu desempenho e qualidade. As empresas que mais progrediram usaram o certificado de qualidade para melhorar os processos internos de suas empresas, ajudando a baixar os custos e aumentar seu foco nos clientes demonstrando que os motivos e orientações na implementação do sistema de gestão são variáveis importantes para se potencializar resultados.

É importante frisar que a certificação ISO9001, no caso de empresas industriais, não garante a qualidade do produto ou serviço final, mas sim sinaliza aos clientes/consumidores que as mesmas:

a) têm capacidade de entregar um produto ou serviço exatamente conforme suas especificações;

b) seguem as melhores práticas em garantia da qualidade e documentação em todos os estágios relevantes da produção. 
c) adotam procedimentos bem definidos e documentados para lidar com problemas logo que detectados;

d) possuem procedimentos para assegurar a rastreabilidade em todos os estágios do desenvolvimento de produtos e de produção, assegurando que as responsabilidades por falhas podem ser identificadas.

e) estão engajadas de melhoria continua e no desenvolvimento de ações preventivas para assegurar que falhas e defeitos sejam consistentemente minimizados.

Assim, a adoção de práticas de gestão da qualidade, conforme recomendado pelas normas ISO9000, como apontados em Nadvi; Kazmi (2001) produz impactos internos e externos à empresa.

Em termos de impactos internos, podem ser citados menores níveis de rejeição, melhor rastreabilidade, maior capacidade de planejar os processos, de identificar seus gargalos e de treinar a força de trabalho para a melhoria contínua da qualidade.

Em termos de impactos externos, a obtenção e manutenção de um certificado ISO9000 estão associados a suas implicações para a governança das cadeias de valor. Por um lado, a certificação pode ser entendida pelos compradores como uma indicação de que o fornecedor possui capacitação mínima para assumir maiores responsabilidades na execução de atividades tecnológicas e organizacionais mais sofisticadas, situação na qual o primeiro procurará colaborará.

Segundo Gallon; Pioli (2009) um estudo realizado com o objetivo de identificar as etapas para implementação da ISO 9000 em uma indústria do plástico de Santa Catarina, considerando a crescente preocupação das indústrias de plástico com a abrangência de novos mercados, principalmente no que se refere a mercados internacionais. Para tanto, realizou-se um estudo exploratório, por meio de um estudo de caso em uma indústria de plástico estabelecida na cidade de Caçador, região centro oeste do Estado de Santa Catarina. O resultado da pesquisa foi segmentado por descrição do processo de obtenção e manutenção da certificação ISO. Observou-se que a indústria de plástico pesquisada busca a manutenção da certificação alcançada há 8 anos. Constatou-se que a qualidade é hoje a meta principal da empresa, por estar intimamente ligada à produtividade e à melhoria de resultados, e esta é obtida especialmente através da redução de perdas/desperdícios e do envolvimento dos colaboradores. Por fim, observou-se que a empresa está satisfeita com a certificação e acredita que a certificação é um diferencial competitivo no mercado de plástico.

Segundo Lee; To; Yu (2009), muito recentemente, estudos mais estruturados tem usado dados conduzidos em diferentes partes do mundo, principalmente em países europeus e 
Estados Unidos. Taylor (1995) apud Lee; To; Yu ( 2009, p.648) conduziu uma pesquisa entre 682 organizações direcionada ao executivos seniores para estudar diferenças organizacionais em práticas de implementação da ISO9001. Este concluiu que diferenças eram significativas entre organizações pequenas, médias e grandes empresas, descreve ainda que pequenas organizações demonstram ter problemas particulares em termos de entendimento da proposta da ISO9001, métodos de medição de seu impacto, e conhecimento sobre os benefícios potenciais. Um lado positivo é que pequenas organizações pareciam mais propensas registrar a buscar todas as atividades. Huarng (1998) apud Lee; To; Yu ( 2009, p.648) que conduziu um estudo sobre as motivações e benefícios para a implementação de ISO9001 em Taiwan, e este concluiu que a norma forneceu benefícios significantes a internacionalização, gerenciamento da qualidade, vendas e redução de custos para pequenas e medias empresas. Este sugere que a norma seja implementada como uma motivação real de melhoria dos negócios e internacionalização e que levaria a melhoria da qualidade com o tempo.

Vloeberghs; Bellens (1996); Wiele ; Brown (1997) apud Wu ; Liu (2010, p. 29), classificaram os indutores de motivação para implantação da ISO 9001 em incentivos internos e externos. Internos incluem cinco itens: melhoria na estrutura organizacional, melhoria da qualidade, criação de procedimentos padronizados, melhoria de imagem da corporação e efetividade de melhoria de gerenciamento. Os incentivos externos incluem quatro itens como: melhoria no cumprimento das demandas, atendimento de contrato, pressão de competidores e expansão de mercado.

Wu; Liu (2010) realizaram um estudo em 177 industrias ótica-eletrônicas em Taiwan com o objetivo: desenvolvimento de indicadores para avaliar industrias certificadas pela ISO9001 e construir um modelo de relação de desempenho para tais industrias. O estudo apresentou o conceito de Balanced Scorecard para a medição de desempenho para as indústrias certificadas e adotou uma modelagem para verificar a relação causal entre as perspectivas de desempenho. Como conclusão estes definiram: Os indicadores estão compreendidos em cinco perspectivas: financeira, clientes, processos internos, aprendizado e crescimento e missão da empresa.

O papel do 5S na organização industrial

Quando entendido e desenvolvido dentro do contexto sem considerar o tamanho ou tipo, o $5 \mathrm{~S}$ pode ser usado para engajar as atividades de melhoria dentro de muitos ambientes incluindo: casas, escolas, comunidades e locais de trabalho (DE MENTE, 1994). Alguns dos benefícios mais importantes da implementação do 5S são resumidos aqui como: 
- Ordenação (seiri e seiton)- para maximizar a eficiência e eficácia pela redução da carga de trabalho de pessoas e erros humanos através da simplificação dos processos;

- Limpeza (seiso e seiketsu)- para maximizar eficácia pela contribuição a uma vida mais saudável, segurança e bem estar tal como transparência;

- Disciplina (shitsuke)- através de treinamento e educação para melhorar o nível de moral a qual leva a aumentar a qualidade de trabalho e de vida e padrões de trabalho (OSADA, 1991).

No Japão é comum que a prática do $5 \mathrm{~S}$ esteja integrada com sabedoria de vida japonesa conhecida como kaizen ( mudança para melhor) e métodos me-de-miru (visual) (KODAMA, 1959). Este sistema integrado de pensamento e gerenciamento torna $m e$-de-miru kanri, o qual é um sistema de controle visual.

$\mathrm{O}$ foco de qualidade tornou-se globalmente aceito em conjunto com outras abordagens japonesas da qualidade (SHIH E GURNANI, 1997). Recentemente, devido à aplicabilidade destas abordagens na tomada de decisão, o $5 \mathrm{~S}$ tem expandindo em aplicações de sistemas de gerenciamento ambiental para apoiar a sustentabilidade (TICE et al, 2005).

O reconhecimento atual do $5 \mathrm{~S}$ na literatura ocidental.

Hyland et al. (2003) refere-se ao 5S como uma ferramenta de solução de problemas. Bamber et al. (2000) sugere que 5S e TPM (Total Productive Maintenance) podem ser utilizados não somente simultaneamente mas também em conjunto com outros métodos de melhoria de processos usados no gerenciamento da qualidade total, kaizen e o just-in-time (JIT) e integrado no gerenciamento ambiental. Esta visão é empiricamente apoiada por Zutshi e Sohail (2005) que identificaram que existem padrões de benchmarking disponíveis em gerenciamento ambiental os quais podem ser usados para alcançar níveis ótimos de operações ou Best Practices na Austrália.

Fatores estruturais de sucesso do 5S na empresa.

Tamanho da empresa e grupo multinacional.

Warwood e Knowles (2004) realizaram um estudo no Reino Unido e analisaram a implementação do $5 \mathrm{~S}$ usando uma amostra de 39 de empresas manufatureiras. Estes não encontraram uma relação estatisticamente significante entre tamanho e o nível de implementação de 5S. Em contraste, Scott et al. (2009) encontrou que industrias de porte médio de alimentos canadenses apresentaram um nível mais alto de empresas manufatureiras usando $5 \mathrm{~S}$.

Grupos multinacionais de empresas também poderiam ser um fator determinante para a incorporação deste tipo de metodologia inovadora para melhoria contínua. Geralmente, 
empresas multinacionais são abertas para novos conhecimentos e mais receptivas as incorporações de mudanças e práticas manufatureiras inovadoras (MERINO 2003).

Tipo de produto e prioridades estratégicas.

O tipo de produto manufaturados podem ser um fator condicionante para o uso de $5 \mathrm{~S}$ na fabrica. Ao invés de ser uma metodologia poderosa uma grande variedade de indústrias, seu uso pode ser afetado pelo tipo de produto manufaturado (intermediário maquinaria ou clientes finais). Numa situação onde o cliente é outra empresa, a relação demanda tanto mais qualidade quanto melhoria contínua. Em contraste, se o cliente final são consumidores, o nível de controle sobre o processo de manufatura é mais baixo desde que o produto não seja parte de outro processo de manufatura.

Analisando a implementação do 5S no Reino Unido e empresas japonesas, Ho et al. (1995) encontraram que não ocorrem diferenças significativas em empresas que utilizam 5S entre serviços e setores de manufaturas. Comparando o entendimento e aplicação em empresas automotivas e não- automotivas em 15 empresas de manufatura no Reino Unido, Herron e Braiden (2006) demonstram que o setor automotivo tem um nível mais alto de entendimento e aplicabilidade de $5 \mathrm{~S}$ que empresas não automotiva. $\mathrm{O}$ setor automotivo demonstra um bom entendimento de 5S (57 \%) embora o nível de uso seja baixo (15\%).

Recursos humanos: envolvimento, treinamento e união

O uso do $5 \mathrm{~S}$ na prática é influenciado por fatores humanos que podem interferir na sua eficácia. (WARWOOD; KNOWLES, 2004). A implementação do 5 S requer comitê para gerenciar os trabalhadores na organização (HO, 1999). Estes citam que o grau de envolvimento de empregados é a mais importante diferença entre as abordagens japonesa e ocidental para a implementação do $5 \mathrm{~S}$.

Gapp et al. (2008) demostram que a participação do trabalhador é requerido para se alcançar os benefícios do 5S. Uma amostra de empresas japonesas, o autor encontrou que gerentes colocaram uma ênfase forte no envolvimento dos empregados, não somente nos aspectos organizacionais, mas também na aplicação estratégica e a longo prazo do sistema.

A metodologia 5S tem sido considerada um pré-requisito para um sistema efetivo de garantia da qualidade (DALE,1999).Quando maquinas e ferramentas estão limpas, uma podese facilmente encontrar problemas e determinar suas causas. Sugerem que os trabalhadores disciplinados aos padrões de trabalho ou práticas de $5 \mathrm{~S}$ tenham um papel crucial nas atividades de melhoria contínua (AOKI, 2007).

O uso do 5S e o desempenho da manufatura.

Especificamente, a implementação do $5 \mathrm{~S}$ ajuda a organizar o ambiente de trabalho 
padroniza o fluxo de trabalho e garante a propriedade limpa do processo aos empregados. Seu rendimento na implementação rapidamente obtém resultados (HIRANO, 1995). No Japão Hartmann (1992) e Willmott (1994) demonstraram que algumas empresas ocidentais, têm alcançado sua competitividade através da aplicação combinada de manutenção produtiva total (MPT) e o 5S. Kumar et al. (2006) demonstra que os sistemas de 5S ajudam a aumentar a produtividade pela redução do tempo de espera em alguns processos e também garante a saúde e segurança de empregados em uma pequena empresa indiana. Gapp et al. (2008) relacionou as melhorias de manufatura à criação de um local de trabalho melhor quando o $5 \mathrm{~S}$ foi implementado. A adoção do $5 \mathrm{~S}$ fornece uma plataforma que, com pequeno esforço, permitiu a organização a satisfazer vários padrões internacionais com mínimos custos.

A Inter-relação do programa $5 \mathrm{~S}$ com outras ferramentas gerenciais

Segundo Sousa et al.(2007) é difícil quantificar os benefícios que o $5 \mathrm{~S}$ pode trazer a uma organização, por ser um processo educacional e contínuo, muitas vezes é introduzido como base para outras ferramentas gerenciais, através de sua interação, com melhorias em outras funções como produção (novos equipamentos, novos processos, novos sistemas); manutenção (técnicas de confiabilidade e manutenibilidade); qualidade (ISO 9001); recursos humanos (políticas); higiene, segurança (OHSAS 18001) e meio ambiente (ISO 14000). Nas organizações já é comum a introdução de um programa estratégico como o $5 \mathrm{~S}$ visando melhorar o desempenho organizacional a partir de contribuições com as demais ferramentas gerenciais, porém a grande falha na sua introdução é a falta de um diagnóstico organizacional, o que pode causar uma sensação de pânico, uma vez que são implementados sem que haja uma preocupação de verificar as sobreposições de algumas ações. $\mathrm{O}$ quadro1 apresenta as contribuições diretas que o programa $5 \mathrm{~S}$ pode trazer a cada ferramenta gerencial, sendo possível avaliar o potencial destas ferramentas, e quanto se podem incorporar de mudanças positivas em todas as dimensões do ambiente organizacional. Sousa et al. (2007) desenvolveram um trabalho que teve por objetivo analisar, em caráter exploratório, o programa 5S, como uma perspectiva de ação estratégica aplicada em uma Companhia da Policia Militar do Estado de São Paulo. A associação do programa 5S com outras ferramentas de qualidades foi necessária, pois ao analisar a implantação do programa, percebe-se que esta serve de suporte para outras ferramentas, não podendo assim, atribuir apenas para a aplicação dos sensos, uma consciência sobre a qualidade. 


\begin{tabular}{|c|c|}
\hline Ferramentas Gerenciais & Contribuições diretas do $5 \mathrm{~S}$ \\
\hline Folha de verificação & Facilita o acesso através da organização (SEITON); \\
\hline Técnicas de Confiabilidade- TC & Procedimentos (SEIKETSU); \\
\hline Programa Zero Defeito- PDZ & Aspectos Físicos (SEIRI, SEITON, SEISO); \\
\hline $\begin{array}{l}\text { Organização Internacional para } \\
\text { Padronização - ISO } 9000\end{array}$ & $\begin{array}{l}\text { Conservação dos recursos (SEIRI); Identificação, } \\
\text { sinalização, manuseio, e rastreamento (SEITON); } \\
\text { Ambiente adequado à qualidade (SEISO); Procedimentos } \\
\text { (SEIKETSU); Cumprimento aos procedimentos } \\
\text { (SHITSUKE); }\end{array}$ \\
\hline $\begin{array}{l}\text { Procedimentos Padrões de } \\
\text { Higiene } \\
\text { Operacional - PPHO }\end{array}$ & $\begin{array}{l}\text { Melhor apresentação do local de trabalho (SEITON e } \\
\text { SEISO); Higiene do ambiente e das pessoas } \\
\text { (SEIKETSU); }\end{array}$ \\
\hline $\begin{array}{l}\text { Desdobramento da Função da } \\
\text { Qualidade - QFD e Kaizen }\end{array}$ & Postura critica e proativa (SHITSUKE); \\
\hline Qualidade Total - TQC & $\begin{array}{l}\text { Aspectos físicos (SEIRI, SEITON, SEISON); } \\
\text { Padronização (SEIKETSU); } \\
\text { Aspecto comportamental (SHITSUKE); }\end{array}$ \\
\hline $\begin{array}{l}\text { Círculo de Controle de } \\
\text { Qualidade - CCQ }\end{array}$ & $\begin{array}{l}\text { Trabalho em grupo, postura crítica e pró-ativa } \\
\text { (SHITSUKE); }\end{array}$ \\
\hline Just in Time - JIT & $\begin{array}{l}\text { Combate ao desperdício. Ter e usar somente o necessário } \\
\text { (SEIRI); }\end{array}$ \\
\hline Manutenção Produtiva - MPT & $\begin{array}{l}\text { Limpeza e inspeção aumentando a performance dos } \\
\text { equipamentos (SEISO); }\end{array}$ \\
\hline ISO 14000 & $\begin{array}{l}\text { Redução do consumo e reutilização (SEIRI); Combate à } \\
\text { poluição e coleta seletiva (SEISO); }\end{array}$ \\
\hline OHSAS 18000 & $\begin{array}{l}\text { Redução/ eliminação das condições inseguras (SIERI, } \\
\text { SEITON, SEISO, } \\
\text { e SHITSUKE); Redução e eliminação de atos inseguros } \\
\text { (SHITSUKE); }\end{array}$ \\
\hline $\begin{array}{l}\text { GMP, HACC, APPCC } \\
\text { (combate à } \\
\text { contaminação de produtos) }\end{array}$ & $\begin{array}{l}\text { Limpeza e combate à contaminação (SEISO); Higiene de } \\
\text { ambiente e das pessoas (SEIKETSU); }\end{array}$ \\
\hline $\begin{array}{l}\text { PDCA (ou MASP - } \\
\text { Metodologia de } \\
\text { Análise e Solução de } \\
\text { Problemas) }\end{array}$ & Postura crítica e pró-ativa (SHITSUKE); \\
\hline $\begin{array}{l}\text { Gestão de Relacionamento com } \\
\text { clientes - CRM }\end{array}$ & $\begin{array}{l}\text { Melhor apresentação do local de trabalho (SEITON e } \\
\text { SEISO); Pontualidade e respeito (SHITSUKE); }\end{array}$ \\
\hline Seis Sigma - SS & Postura crítica e pró-ativa (SHITSUKE); \\
\hline $\begin{array}{l}\text { Controle Estatístico de } \\
\text { Processos - CEP }\end{array}$ & $\begin{array}{l}\text { Condições favoráveis para controle (SEIRI, SEITON e } \\
\text { SEISO); Confiabilidade dos dados (SHITSUKE). }\end{array}$ \\
\hline
\end{tabular}

QUADRO 1 - A Inter-relação e os benefícios do programa 5S para as outras ferramentas gerenciais.

Fonte: Adaptado de Ribeiro (2006). 


\section{METODOLOGIA}

O método de pesquisa adotado para este trabalho foi estudo de caso, dentro de uma abordagem qualitativa. Justifica-se sua adoção com base na afirmação de Yin (2001), que define o estudo de caso como a estratégia adequada quando se colocam questões do tipo "como" e "por que", quando o pesquisador tem pouco controle sobre os eventos e quando o foco se encontra em fenômenos contemporâneos inseridos em algum contexto da vida real.

Para composição deste estudo de caso, foi utilizada uma amostra não probabilística e intencional, que contemplou uma empresa moveleira de São Paulo- SP. Para a coleta de dados foram utilizadas entrevista semi-estruturada, além da análise de documentos fornecidos pela empresa e observação local através de filmagens e fotos.

\section{ESTUDO DE CASO}

A empresa analisada encontra-se instalada na cidade de São Paulo, em atividade desde 1975. É uma empresa de grande porte, com marca reconhecida dentro do ramo e participante do comércio de mesas, linha de arquivamentos (armários e gaveteiros), biombos, divisores PI, cadeiras, sofás e estações de trabalho para escritórios em geral. Atualmente à empresa conta com cerca de 200 colaboradores, distribuídos em diversas áreas, sendo deste total, 50 na parte fabril. A empresa atualmente é certificada pela ISO 9001:2008.

\section{Motivações para implantação da NBR ISO 9001 e situação operacional anterior a implantação do 5S.}

No início de 2009 a alta administração da organização deparou-se com algumas barreiras relacionadas ao setor de vendas. Como a empresa destina seus móveis para grandes empresas e na maioria a venda se dá por processos de licitações, os clientes estabeleciam inúmeros requisitos obrigatórios para atender suas necessidades e na maioria das vezes, os móveis da empresa não atendiam estas especificações.

A seguir estão descritos os problemas nos diversos setores de produção da moveleira.

Estoque de matéria-prima

Como mencionado anteriormente, a empresa apresentava um sério problema relacionado à falta de área em toda a fábrica e o setor de estoques de matéria-prima principalmente.

Os fatores que contribuíam para a identificação deste gargalo no local eram: 
-Presença de resíduos diversos, especialmente os gerados nos processos de seccionamento;

-Acúmulo de peças semi-acabadas de outros setores;

-Falta de organização quanto à disposição da matéria-prima;

-Painéis diferentes armazenados em uma mesma pilha;

Todos estes aspectos detectados no setor geravam como conseqüências:

-Perda de qualidade da matéria-prima, podendo ocasionar empenamentos, amassados e riscos, como na Figura 1.

-Redução da área útil de estocagem;

-Perda de flexibilidade produtiva e produtividade devido à falta de organização na disposição e armazenamento da matéria-prima;

-Aumento de custos devido ao gerenciamento dos estoques inadequado

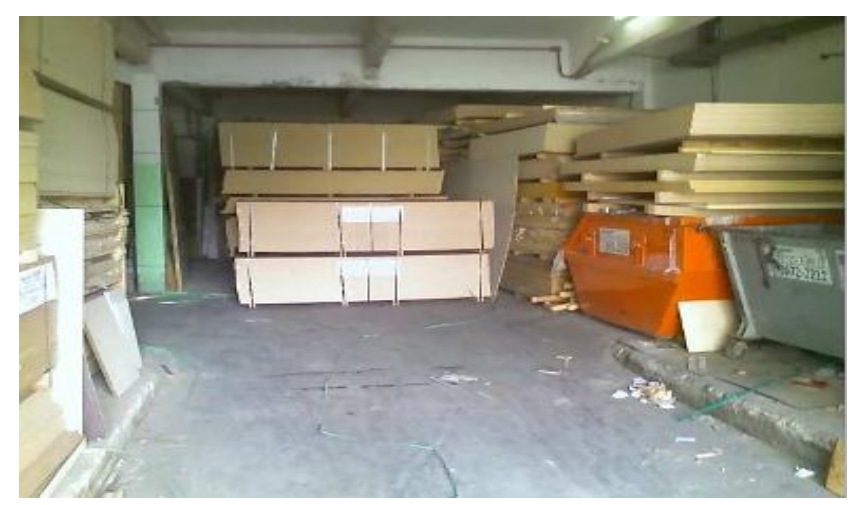

Figura 1. Empilhamento incorreto de painéis como matéria prima.

Setor de Seccionamento

Processo gerava resíduos que eram alocados próximos ao equipamento de seccionamento e do setor de estoque de matéria-prima.

Toda esta estocagem se dava de maneira desordenada, sem nenhuma classificação e preocupação em relação ao destino final destes produtos.

Como conseqüência desta falha organizacional dava - se:

-Dificuldade de fluxo produtivo;

-Não utilização das sobras de painéis;

-Perda de interesse dos colaboradores, em propor soluções viáveis para o melhoramento;

-Falta de identificação de produtos não-conformes, estando estes alocados de modo e local inapropriados.

Setores de Colagem de bordas, processo de furação e cavilhamento

Neste setor, os principais problemas enfrentados eram: 
-Configuração de layout, onde os equipamentos estavam localizados muito próximos;

-Ausência de gerenciamento de estoques intermediários entre processos produtivos;

-Presença de produtos não utilizados no setor de estoques intermediários;

-Presença de produtos não-conformes sem identificação;

-Despreparo dos colaboradores para operar máquinas deste setor;

-Perda de confiabilidade produtiva;

-Falta de segurança.

Setor de estocagem

Como a empresa possuía uma fábrica de dois pavimentos, todas as peças semi-prontas que eram armazenadas na parte inferior eram transportadas até um local de estocagem no pavimento superior. Deste ponto as peças seguiam o processo de acabamento de acordo com o pré-estabelecido.

Os principais problemas encontrados neste setor foram:

-Perda de tempo produtivo na movimentação e devido à desorganização do setor, onde não ocorria nenhuma classificação dos materiais quanto a dimensões, funcionalidade e acabamento, aumentando o tempo de busca;

-Ausência de transportadores para movimentação de componentes;

-Presença de biombos, vidros e peças embaladas no setor, ocupando área útil.

Setor de Prensagem

Como não existia um local específico para o acondicionamento, as peças ficavam alocadas diretamente no chão, local que não apresentava as condições adequadas para o procedimento, podendo aumentar a possibilidade de uma colagem desuniforme, aparecimento de defeitos, além de ocuparem uma determinada área útil no setor.

Setores de Lixamento e Secagem Ultra Violeta

O principal problema no setor era em relação às lixas, pois eram vulneráveis a variações de umidade e temperatura, onde quaisquer alterações no local provocaria perda de resistência e alteração na qualidade do lixamento.

A empresa não possuía local apropriado com temperatura e umidade controlada para um bom armazenamento, com isso o processo de lixamento possuía menor rendimento. As peças saiam do processo com acabamento superficial com baixa qualidade e as lixas apresentavam menor vida útil.

Setores de pintura e secagem das peças

O setor de pintura e secagem alocados no mesmo local, não possuia sistema de insuflação, exaustão, controle de temperatura, luminosidade adequada, circulação do ar, 
controle de umidade relativa interna, rotação de peças e nem separação entre setor de pintura e secagem.

Conseqüentemente, o processo apresentava duração mais prolongada, ocorrência de secagem desuniforme, menor produtividade e maior probabilidade de ocorrência de impurezas na película de acabamento (defeitos de contaminação).

Outro fator crítico era em relação à secagem de peças fora do setor de pintura. A área era improvisada destinada para secar peças quando o setor já estava lotado de componentes, sendo utilizado a curto prazo para solucionar o problema de falta de espaço.

Este local não apresentava separação com outros setores da empresa, ficando ao lado do setor de lixamento. Como consequiência, as peças secas neste setor apresentavam tempo de secagem superior e maior possibilidade de ocorrência de impurezas na película de acabamento, se comparadas às peças secas dentro do setor.

Setores de montagem e fixação de componentes

Em toda a organização estes setores eram o que apresentavam de maior rotatividade de funcionários. A presença de funcionários sem treinamentos, sem habilidades na função de montagem, gerava problemas relacionados ao não cumprimento de prazos, produtos sem qualidade, geração de resíduos e dificuldades em manter funcionários fixos no setor.

Outro fator relevante era dificuldade em ordenar o fluxo produtivo, pois existiam um grande número de peças, componentes e tipos de móveis a serem montados.

Outro fator extremamente crítico na organização esta relacionado à defasagem dos funcionários dos setores de limpeza e montagem de mesas, em relação ao conhecimento da função que desempenhavam no setor tais como: falta de conhecimento dos tipos de tampos e mesas fabricados pela empresa, de componentes necessários para montagem de mesas pouca habilidades para realizar a montagem de mesas sendo que grande parte dos funcionários se concentravam apenas na limpeza de tampos; utilização incorreta de trenas e outros instrumentos de medição. O setor era constituído de vários funcionários, onde apenas dois destes colaboradores juntamente com o supervisor do setor realizavam as operações de gabaritação de furação e montagem das mesas;

\section{Ações propostas para a melhoria da área fabril.}

Com relação à situação precária dos setores produtivos apresentados, foi aceita a proposta de melhorias aos processos para alcançar a certificação do Sistema de Gestão da Qualidade baseado na norma NBR ISO 9001:2008, apresentada pela alta gerência, sendo o 
5S como primeiro passo para organizar a área fabril para alcançar a certificação ISO 9001:2008.

Implantação da Metodologia 5S

Para iniciar o programa, a primeira etapa foi enumerar à alta direção, os problemas existentes na organização e mostrar os benefícios que o programa 5S iria incorporar a empresa. Como uma das principais vantagens demonstradas, foi que a implantação do programa 5S seria o ponto inicial básico para a empresa alcançar a Certificação de Gestão da Qualidade baseada na norma NBR ISO 9001:2008.

A partir dos resultados, realizou-se um planejamento para implantação do programa 5S, contendo: cronograma de implantação; cartilhas com explicações dos cinco sensos e vantagens da implantação do programa; procedimento da implantação do programa, contendo as etapas de implantação, a divisão de tarefas referentes à conscientização, divulgação, palestras, treinamentos e sensibilização dos colaboradores; desenvolvimento de quadros informativos e melhorias no layout da área fabril; medição de materiais para descarte; implantação de quadros informativos contendo metas produtivas para cada setor

O intuito de colocar estes quadros em cada setor foi demonstrar aos colaboradores a quantidade de produtos produzidos por estes, juntamente com a intenção de demonstrar sua importância junto à organização, além de mostrar que seu trabalho era importante para sobrevivência da empresa. Antes de qualquer implantação, foi explicada com cada responsável, a utilidade destes quadros produtivos.

Em seguida, a alta direção estabeleceu os setores que iriam receber os quadros produtivos com suas respectivas metas.

A seguir, encontra-se a Figura 2, demonstrando o quadro produtivo com o número de chapas seccionadas nos turnos da manhã e noite no setor de usinagem.

\begin{tabular}{|c|c|c|c|c|c|c|c|c|}
\hline \multicolumn{7}{|c|}{ Metas: } \\
\hline Setor: & CHAPAS CORTADAS: 110/TURNO & \\
\hline & DOITE & DATA & DIA & NOITE & DATA & DIA & NOITE \\
\hline DATA & DIA & NOTIVA & 21 & & \\
\hline 1 & & & 11 & & & 22 & & \\
\hline 2 & & & 12 & & & 23 & & \\
\hline 3 & & & 13 & & & 23 & & \\
\hline 4 & & & 14 & & & 24 & \\
\hline 5 & & & 15 & & & 25 & & \\
\hline 6 & & & 16 & & & 26 & & \\
\hline 7 & & & 17 & & & 27 & & \\
\hline 8 & & & 18 & & & 28 & & \\
\hline 9 & & & 19 & & & 29 & & \\
\hline 10 & & & 20 & & & 30 & & \\
\hline & & & & & & 31 & & \\
\hline
\end{tabular}

Figura 2 Quadro de meta produtiva 
Todos os dias pela manhã antes de iniciar o turno de trabalho, o supervisor anotava no quadro a produtividade, responsabilizando-se pela atualização das informações.

Para facilitar a observação das metas foi também desenvolvido um quadro com as metas de todos os produtos da empresa onde as marcações eram indicadas em porcentagens, com o intuito de facilitar a compreensão dos dados.

A partir destes problemas, foi concluído que a alta direção não realizava treinamentos junto aos colaboradores e nem ao menos os supervisores passavam seus conhecimentos aos demais trabalhadores.

Quadro informativo no setor de Planejamento e Controle do Processo, baseado no Sistema Kanban

Neste quadro constavam todos os dados necessários para facilitar o controle e planejamento dos processos produtivos. Na figura 3 abaixo observa-se os espaços para preenchimento das O.D( Ordens de Produção) e para suas datas de vencimento. É constituído também de todas as etapas dos processos produtivos: Usinagem; Acabamento; Serralheria; Tapeçaria; Armários e gaveteiros; Montagem; Expedição.

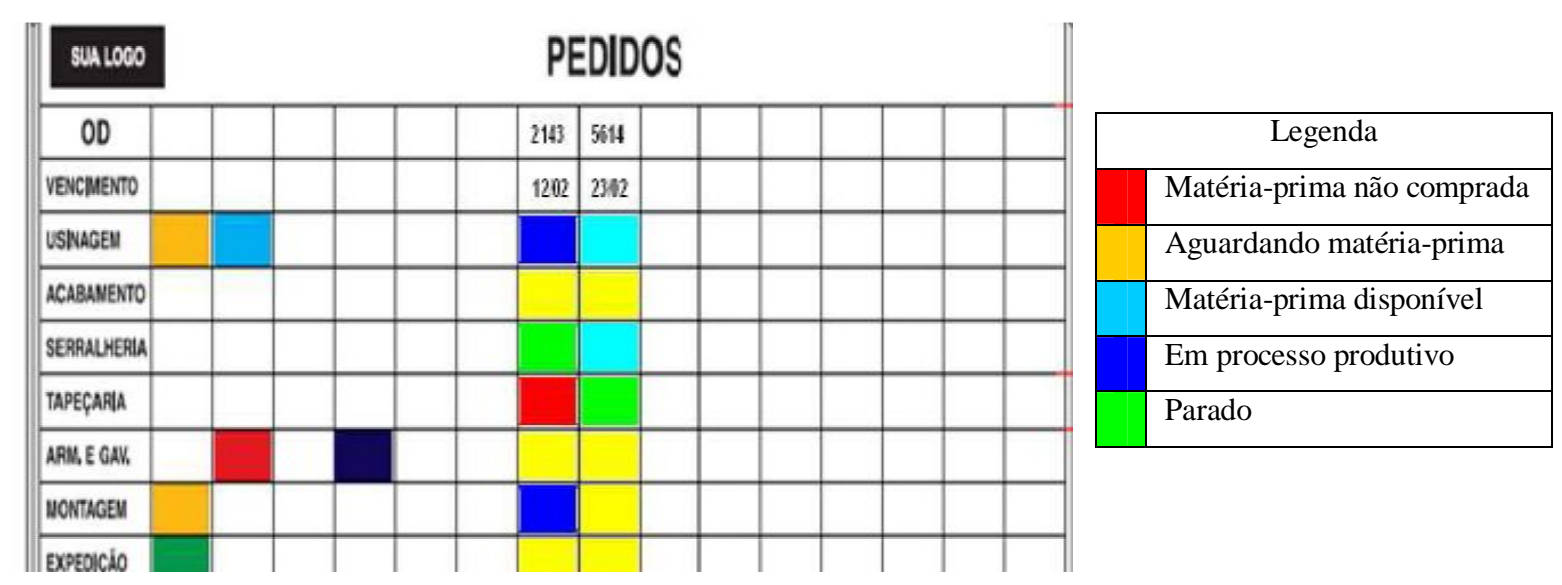

Figura 3. Quadro informativo no setor de Planejamento e Controle do Processo, baseado no Sistema Kanban.

O sistema de marcação do quadro consistiu no seguinte esquema. As marcações eram feitas com mantas magnéticas coloridas, onde cada cor representava uma situação dentro de um determinado processo produtivo.

Através destas informações, cada responsável saberia a situação real do processo produtivo de sua responsabilidade ou de etapas dependentes para sua fabricação.

Setor de estocagem de peças semi-acabadas. 
O procedimento de controle de estoques de produtos semi-acabados definia que todos os tampos que fossem armazenados neste setor deveriam ser estocados nos box's verdes (estruturas criadas para armazenar tampos sem provocar defeitos e ocupar da melhor maneira possível o espaço do setor).

O procedimento de recebimento e retirada de materiais semi-acabados para montagem do setor definia que todo o lote de peças que chegasse ao setor de armazenamento, deveria ser verificado e identificado, determinando um local pré-estabelecido que permitisse um armazenamento com qualidade, organização, facilidade de acesso e segurança; todos os Box verdes conteriam "Fichas de Prateleira" que deveriam ser atualizadas tanto no armazenamento quanto na retirada das peças do setor. As "Fichas de Prateleira", conteriam os dados do material (funcionalidade, acabamento e dimensões e identificação do funcionário responsável pela atividade. Os demais materiais como: Abafadores, Painéis - PI's, Biombos, Pé painel, Painel frontal e demais produtos, deveriam ser armazenados somente sobre pallets, também contendo as Fichas de Prateleira ( figura 4 ) abaixo.

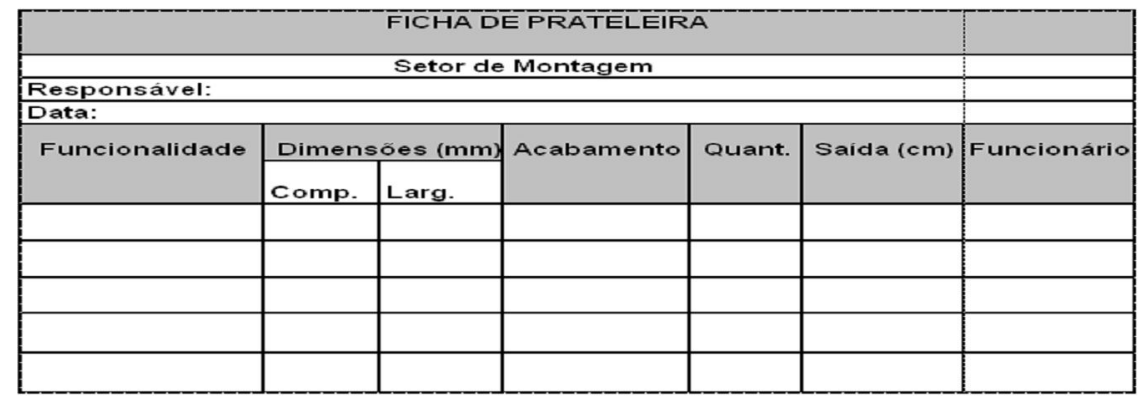

Figura 4. Ficha de Prateleira.

Ocorreram treinamentos para os funcionários do setor de montagem, com intuito de ensinar a maneira correta de utilização de trenas, pois os produtos estavam sendo produzidos em não conformidade com as especificações, tipos de tampos e suas peculiaridades; os acabamentos superficiais existentes nos tampos e o uso correto das Fichas de Prateleira no setor de estocagem de peças semi-acabadas. Além destas tentativas de melhoria, o setor de montagem ainda estava defasado em relação à dificuldade em determinar os componentes, como: calhas, pé painéis e painéis frontais nas dimensões corretas para a montagem das mesas. A Figura 5 mostra o quadro ilustrativo de tampos, para melhor entendimento e ilustração. 


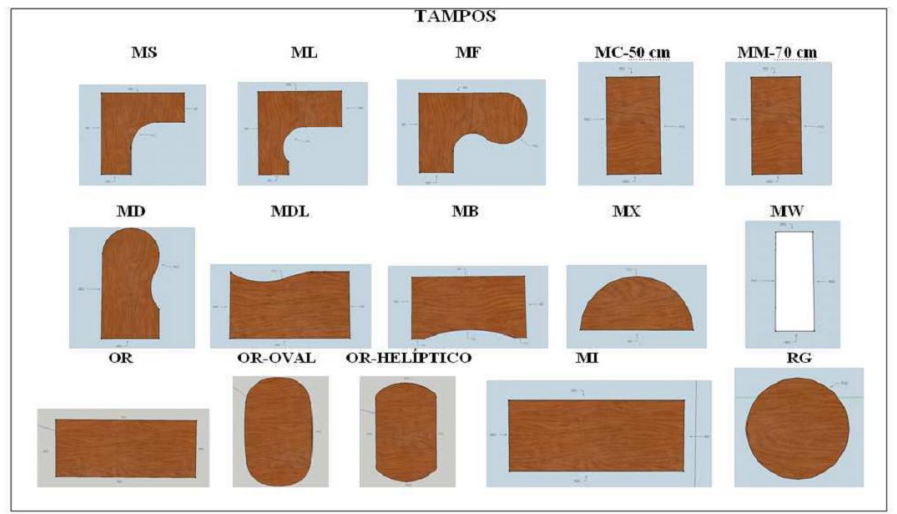

Figura 5. Quadro ilustrativo de diferentes tipos de tampos

O motivo da utilização de siglas para diferenciar os tipos de tampos tinha como objetivo simplificar seus nomes.

A linha de mesas que apresentavam maior dificuldade em relação a estes aspectos era a Gama. Para sanar estes problemas, foi proposta um manual com procedimentos de montagem, onde continha todos os componentes necessários com suas respectivas dimensões, para a montagem correta das mesas ilustrada na Figura 6.

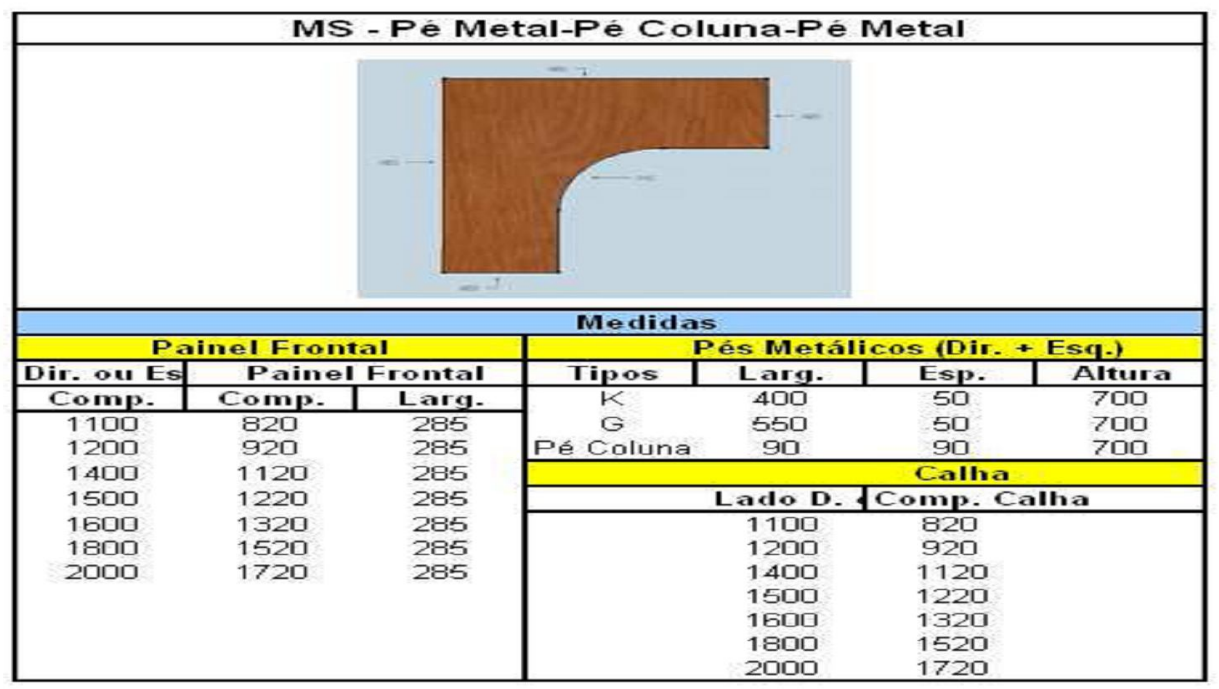

Figura 6. Descrição de peças para montagem de montagem de produtos da Linha Gama.

\section{RESULTADOS DA IMPLANTAÇÃO DO 5S NA INDÚSTRIA MOVELEIRA.}

\section{A seguir são descritos resultados nos vários setores da área fabril da empresa estudada.}

Com a implantação dos quadros de controle e ações os principais resultados foram:

-Redução de produtos não-conformes nos diferentes setores;

-Melhor utilização do espaço para armazenamento; 
-Melhor empilhamento dos materiais;

-Aumento na preocupação dos colaboradores em manter o ambiente de trabalho organizado;

-Redução do tempo de procura de uma determina peça pelos colaboradores;

Como conseqüências destas ações, ocorreram algumas mudanças de comportamento nos funcionarios, como:

-O setor de estoque de ferragens procurou ajuda para organização do setor;

-Funcionários do setor de usinagem, expedição e ferragens, conscientizaram-se da responsabilidade em organizar seus setores;

-Os colaboradores e supervisores implantaram no setor de ferragens uma Ficha de Biombos para identificação (peças que mais ocupavam espaço no setor);

-O corredor central destinado ao fluxo de funcionários e transporte de materiais tornou-se desbloqueados de materiais.

Em relação à alta direção, foi observado que estes não possuíam dados reais e confiáveis da produtividade da organização, não possuíam nem ao menos uma estimativa aproximada deste valor. Logo, com a implantação dos quadros produtivos obteve-se:

-Melhor planejamento produtivo;

-Visualização do desempenho da produtividade em relação às metas produtivas;

-Percepção sobre quais os setores mais críticos e problemáticos na organização, focando seus esforços nestes locais.

Ainda em relação aos colaboradores, foi observado que estes inicialmente não se importavam com a marcação da produtividade, achando que seria inferior ao estipulado pela alta direção e seriam criticados pelo proprietário. Ao final do primeiro mês, quando observaram que alcançaram ou chegaram próximos aos valores impostos como metas produtivas pelos diretores, perceberam a importância destes.

\section{CONCLUSÃO}

Considerando tudo que foi discutido em relação às estratégias e competitividade nas organizações, pode-se concluir que implantar uma gestão de qualidade seguindo os passos da filosofia $5 \mathrm{~S}$, serve como importante base para um futuro programa de qualidade que a empresa queira implantar, visando uma certificação de qualidade.

Um ambiente, que funcionários estejam vivendo em harmonia no seu espaço de trabalho, se sentido estimulado, a ponto de apontar problemas e sugerirem na transformação, já que estão incluídos na mudança pode levar a melhoria organizacional. Foi fácil observar, 
que em todo processo de implementação do programa 5S, pouco se percebe a necessidade de custos nos procedimentos, mesmo porque até os treinamentos, que devem ser feitos com certa freqüência, pode ser ministrado pelos funcionários que poderão se aperfeiçoar através de livros e informática. Ou seja, um investimento maior realizou-se na conscientização para mudança de comportamento e atitudes, o que é essencial, para gerar motivação, maior entrosamento entre os funcionários, um ambiente organizado limpo e sadio. No início da implantação, os colaboradores não possuíam o bom senso em relação à responsabilidade que o controle e gerenciamento do setor dependiam de seus esforços levando ao reflexo das melhorias observadas no setor de estoques de peças semi-acabadas. Apesar da falta de escolaridade dos funcionários, descomprometimento da alta direção, desmotivação dos funcionários, falta de treinamento, resistência a mudança cultural, carência de pessoas qualificadas para implantar a certificação da ISO 9001, houve uma grande aceitação do uso de ferramentas de organização industrial.

Ainda sobre a empresa estudada, observou-se uma diferença significativa quanto ao ambiente que, após a implantação do 5S, mostrou-se um ambiente motivador, limpo, organizado, ou seja, tudo que o programa propõe,quando em comparação quando a situação anterior ao programa quando foi observado um ambiente, escuro, sujo, sem padronização e metas á produção esperada dos colaboradores. Verificou-se ainda que a implantação desse programa baseado nas informações fornecidas pelo programa de $5 \mathrm{~S}$, junto com a conscientização e participação de todos gerou a esta, inúmeros benefícios, como redução dos tempos de fabricação, redução de custos, racionalização do espaço físico, adequação dos estoques, ganhos de produtividade, melhoria da qualidade e maior competitividade.

\section{REFERÊNCIAS}

ANSARI, A. ,MODARRESS, B. World-class strategies for safety: a Boeing approach. International Journal of Operations \& Production Management, v. 17,n. 4, 1997.p. 389398.

BAMBER, C.J.; SHARP, J.M.; HIDES, M.T. Developing management systems towards integrated manufacturing: a case study perspective. Integrated Manufacturing Systems. v. 11 n. 7. 2000. p. 454-461.

CHIN, K.S. AND PUN, K.F. A proposed framework for implementing TQM in Chinese organizations. The International Journal of Quality \& Reliability Management. v. 19, n.2. p. 272.2002 . 
DALE, B.G. The Japanese approach to TQM". Managing Quality, 3. ed. Oxford: Blackwell, p. 51-83. 1999.

DA SILVEIRA, G.J.C.Effects of simplicity and discipline on operational flexibility: an empirical reexamination of the rigid flexibility model. Journal of Operations Management. v. 24 , n. 6. p. $932-947.2006$.

DE MENTE, B.L. Japanese Etiquette and Ethics in Business. 6. ed., Lincolnwood, IL. : NTC Business Books, 1994.

DICK, Gavin P. M. Electronic publishing: ISO 9000 certification benefits, reality or myth? (Staffordshire University, Business School) TQM Magazine, v 12, n 6, 2000p.

GALLON, A. V.; PIOLI, F. L.S. Identificação das etapas para implementação e certificação em uma indústria de plástico catarinense. In: XVI SIMPEP, 2009, Bauru. Anais... Bauru, 2009.

GAPP, R.; FISHER, R.; KOBAYASHI, K.Implementing 5S within a Japanese context: an integrated management system. Management Decision. v. 46, n. 4. p. 565-579.2008.

HARTMANN, E. Successfully Installing TPM in a Non-Japanese Plant, Allison Park, PA: TPM Press, 1992.

HERRON, C.; BRAIDEN, P.M. A methodology for developing sustainable quantifiable productivity improvement in manufacturing companies. International Journal of Production Economics, v.4, n.1, p. 143-153. 2006.

HIRANO, H. in Talbot, B. (Ed.), Five Pillars of the Visual Workplace: The Sourcebook for 5S Implementation, New York, NY: Productivity Press, 1995

HO, S.K.M.; CICMIL, S. ; FUNG, C.K. The Japanese 5-S practice and TQM training. Training for Quality. v. 3, n. 4, p. 19-24.1995.

HYLAND, P.et al. A comparison of Australian firms and their use of continuous improvement tools. The TQM Magazine. v. 12, n. 2, p. 117-124.2000

KODAMA, R. Medemiru Kaizen dokuhon, Nikkan Kogyo Shinbunsha, Tokyo.1959.

KUMAR M.et al.Implementing the Lean Sigma framework inan Indian SME: a case study, Production Planning \& Control, v.17, p.407 - 423, 2006,

LEE, Peter K.C.; TO, W.M.; YU, T.W. The implementation and performance outcomes of ISO9001 in services organizations. An empirical taxonomy. International Journal of Quality \& Reliability Management. v. 26, n. 7, p. 646-662, 2009.

MERINO, J. Quality management practices and operational performance: empirical evidence for Spanish industry. International Journal of Production Research. v. 41, n. 12, p. 27632786.2003.

NADVI,K.; KAZMI,S. Global standards and local responses. In: WORKSHOP ON THE IMPACT OF GLOBAL AND LOCAL GOVERNANCE ON IDUSTRIAL UPGRADING, 1317, Brighton., feb. 2001. 
OSADA, T. 5S - Tezukuri no manajiment shuho- (5S - Handmade Management Method). Tokyo: JIPM,1989.

OSADA, T. The 5S's: Five Keys to a Total Quality Environment. Tokyo: Asian Productivity Organisation, 1991.

RAMOS, M.Y. Impactos organizacionais da adoção de normas ISO9000: Estudos de casos na cadeia de Embalagens PET para bebidas. São Paulo, 2004. Dissertação ( Mestrado em Administração), Universidade de São Paulo.

RIBEIRO,A. A bíblia do 5S, da implantação à excelência. Salvador: Casa da qualidade, 2006, 150p.

SCOTT, B.S.; WILCOCK, A.E.; KANETKAR, V. A survey of structured continuous improvement programs in the Canadian food sector. Food Control. v. 20, p. 209-217.2009.

SHIH, L.C. AND GURNANI, H. Global quality management programmes: how to make their implementation more effective and less culture dependent. Total Quality Management. v. 8, n. 1, p. 15-31.1997.

SOUSA, A.A.et al. Programa 5S: o caso de uma Companhia da Policia Militar do Estado de São Paulo. Simpep 2007. 11p.

TICE, J.; AHOUSE, L.; LARSON, T. Lean production and EMSs: aligning environmental management with business priorities. Environmental Quality Management. v. 15, n. 2, p. 112.2005 .

WARWOOD, S.J. AND KNOWLES, G. An investigation into Japanese 5 S practice in UK industry. The TQM Magazine. v. 16, n. 5, p. 347-353. 2004.

WILLMOTT, P.Total Productive Maintenance: The Western Way, New York, NY : Butterworth-Heinemann,.1994.

WU, S.; LIU, S. The performance measurement perspectives and causal relationship for ISSO- certified companies. A case of opto-electronic industry. International Journal of Quality \& Reliability Management. v. 27, n . 1, p. 27-47, 2010.

ZUTSHI, A. AND SOHAL, A.S. Integrated management system: the experiences of three Australian organizations. Journal of Manufacturing Technology Management. v. 16, n. 2, p. 211. 2005.

YIN, R. K. Estudo de caso: planejamento e métodos. Porto Alegre: Bookman, 2001. 
